\title{
Authors' reply: the biologic importance of the vitamin $D$ binding protein polymorphism in pediatric COVID-19 patients
}

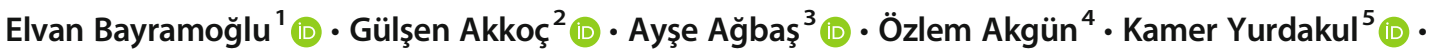 \\ Hatice Nilgün Selçuk Duru ${ }^{4}$ (D) Murat Elevli ${ }^{4}$ (D)
}

Received: 30 April 2021 / Revised: 30 April 2021 / Accepted: 6 May 2021 / Published online: 14 May 2021

(C) The Author(s), under exclusive licence to Springer-Verlag GmbH Germany, part of Springer Nature 2021

What is Known?

- Vitamin D has multiple roles in the immune system that can modulate the body reaction to an infection

- Vitamin D binding protein (DBP) is the key transport protein which, along with albumin, binds over 99\% of the circulating vitamin D metabolites

What is New?

- Lower $25 \mathrm{OH}$ vitamin D levels were associated with higher inflammation markers, suggesting an important role of vitamin D in the clinical course of COVID-19 in children and adolescents probably by regulating the systemic inflammatory response

- Further studies are warranted to investigate the possible causal association of DBP levels and polymorphism with vitamin D status (total and bioavailable vitamin D) in COVID-19 patients

Keywords COVID-19, Vitamin D, Vitamin D binding protein

We would like to thank Speeckaert et al. for their interest in our study and for providing an insightful perspective on vitamin D binding protein (DBP) level or polymorphism as a possible explanation for the association between vitamin $\mathrm{D}$ status and COVID-19 outcomes.

The authors mentioned their previous study that the DBP1 allele frequency, which affects DBP concentration, was associated with lower prevalence and mortality due to SARSCOV-2 infection $[1,2]$. Total $25(\mathrm{OH}) \mathrm{D}$ is defined by the DBP-bound fraction [approximately $85-90 \%$ of total $25(\mathrm{OH}) \mathrm{D}]$, the albumin-bound fraction $[10-15 \%$ of total

Communicated by Peter de Winter

Elvan Bayramoğlu

elvanbayramoglu@gmail.com

Gülșen Akkoç

agulsenakkoc@gmail.com

Ayșe Ağbaş

yurtayse@hotmail.com

Özlem Akgün

drozlemakgun@hotmail.com

Kamer Yurdakul

kamer_dogan@yahoo.com

Hatice Nilgün Selçuk Duru

nilgunduru@yahoo.com
$25(\mathrm{OH}) \mathrm{D}]$, and the free circulating fraction $[<1 \%$ of total $25(\mathrm{OH}) \mathrm{D}]$. According to the free hormone hypothesis, vitamin D, which can enter the cell and have a biological effect, is in free form. It has been reported that DBP level and polymorphism affect the serum $25 \mathrm{OH}$ vitamin D levels by changing the binding affinity to vitamin D, and also DBP may have an effect on $25(\mathrm{OH})$ vitamin $\mathrm{D}$ related intracrine responses. Bioavailable vitamin D (not bound to DBP) is thought to be more biologically active in target tissues [3].

We agree with Speeckaert et al. that DBP polymorphism or concentration along could be a possible link for the
Murat Elevli

muratelevli@gmail.com

1 Department of Pediatric Endocrinology, University of Health Sciences Haseki Training and Research Hospital, Istanbul, Turkey

2 Department of Pediatric Infectious Diseases, University of Health Sciences Haseki Training and Research Hospital, Istanbul, Turkey

3 Department of Pediatric Nephrology, University of Health Sciences Haseki Training and Research Hospital, Istanbul, Turkey

4 Department of Pediatrics, University of Health Sciences Haseki Training and Research Hospital, Istanbul, Turkey

5 Department of Biochemistry, University of Health Sciences, Haseki Training and Research Hospital, Istanbul, Turkey 
Table 1 Correlations of $25 \mathrm{OH}$ vitamin D with calcium, phosphorus, and parathormone

\begin{tabular}{lll}
\hline & $r$ & $p$ Value \\
\hline Calcium (mg/dL) & 0.330 & 0.001 \\
Phosphorus (mg/dL) & 0.431 & $<0.001$ \\
Parathormone (pg/mL) & -0.287 & 0.023 \\
\hline
\end{tabular}

association between vitamin D status and COVID-19 outcomes. Although there are opinions that measuring the bioavailable vitamin $\mathrm{D}$ is more reliable to evaluate vitamin D activity and adequacy, serum $25 \mathrm{OH}$ vitamin $\mathrm{D}$ level has been measured in most of the studies. As PTH increases in vitamin D deficiency, it is thought that PTH is a useful indicator of low vitamin D level $[4,5]$. In our retrospective study, we evaluated the vitamin D status with $25 \mathrm{OH}$ vitamin D. The vitamin D-deficient group had significantly lower calcium, phosphorus, and higher PTH levels. In addition, $25 \mathrm{OH}$ vitamin D levels were positively correlated with calcium and phosphorus levels and negatively with the PTH levels demonstrating the reliability of $25 \mathrm{OH}$ vitamin $\mathrm{D}$ levels to assess vitamin D bioactivity (deficiency) in our cohort (Table 1). There can be several reasons of the low 25 $\mathrm{OH}$ vitamin D level such as decreased intake, decreased biosynthesis due to lack of sun exposure, or as Speeckaert et al. stated DBP level or polymorphism.

In summary, our study shows the relationship between vitamin D deficiency and the clinical severity of COVID19 and inflammatory markers. Further studies are warranted to investigate the possible causal association of DBP levels and polymorphism with vitamin D status (total and bioavailable vitamin D) in COVID-19 patients, as suggested by Speeckaert et al.
Author contribution EA, AA, and GA wrote the manuscript. EB, GA, $\mathrm{KD}, \mathrm{OA}, \mathrm{AA}, \mathrm{HNSD}$, and ME reviewed the manuscript.

Data availability The authors declare that (the/all other) data supporting the findings of this study are available within the article (and its supplementary information files).

Code availability Not applicable.

\section{Declarations}

Conflict of interests The authors declare no competing interests.

\section{References}

1. Speeckaert MM, Speeckaert R, Delanghe JR (2021) Vitamin D sufficiency and COVID-19: is vitamin D binding protein (and its polymorphism) the missing link? Endocr Pract. https://doi.org/10.1016/j. eprac.2021.03.011

2. Speeckaert MM, De Buyzere ML, Delanghe JR (2021) Vitamin D binding protein polymorphism and COVID-19. J Med Virol 93(2): 705-707

3. Bikle DD, Schwartz J (2019) Vitamin D binding protein, total and free vitamin D levels in different physiological and pathophysiological conditions. Front Endocrinol (Lausanne) 10:317. https://doi.org/ 10.3389/fendo.2019.00317

4. Chun RF, Shieh A, Gottlieb C, Yacoubian V, Wang J, Hewison M, Adams JS (2019) Vitamin D binding protein and the biological activity of vitamin D. Front Endocrinol (Lausanne) 10:718. https://doi. org/10.3389/fendo.2019.00718

5. Goldner WS, Stoner JA, Thompson J, Taylor K, Larson L, Erickson J, McBride C (2008) Prevalence of vitamin D insufficiency and deficiency in morbidly obese patients: a comparison with nonobese controls. Obes Surg 18(2):145-150

Publisher's note Springer Nature remains neutral with regard to jurisdictional claims in published maps and institutional affiliations. 